\title{
Household fuel use and child respiratory ill health in two towns in Mpumalanga, South Africa
}

\author{
P N Albers, ${ }^{1,2}$ MSc; C Y Wright, ${ }^{1,3,4} \mathrm{PhD} ; \mathrm{K}$ V V Voyi, ${ }^{2} \mathrm{PhD} ;$ A Mathee, ${ }^{1,5} \mathrm{PhD}$ \\ ${ }^{1}$ Environment and Health Research Unit, Medical Research Council, Johannesburg, South Africa \\ ${ }^{2}$ School of Health Systems and Public Health, Faculty of Health Sciences, University of Pretoria, South Africa \\ ${ }^{3}$ Climate Studies, Modelling and Environmental Health Research Group, Council for Scientific and Industrial Research, Pretoria, South Africa \\ ${ }^{4}$ Department of Geography, Geoinformatics and Meteorology, Faculty of Natural and Agricultural Sciences, University of Pretoria, South Africa \\ ${ }^{5}$ Faculty of Health Sciences, University of Johannesburg, South Africa
}

Corresponding author: P N Albers (pnalbers@gmail.com)

\begin{abstract}
Background. This cross-sectional study examined respiratory health outcomes and associated risk factors in children living in a part of South Africa characterised by high levels of air pollution.

Methods. A questionnaire was used to collect self-reported respiratory health and risk factor data from the parents/guardians of children between the ages of 9 and 11 years attending primary schools in the study area. Six government schools were selected based on their location, class size and willingness to participate. Univariate and bivariate analyses as well as logistic regression analysis were performed on the data, using a $p$-value of 0.25 and biological plausibility.

Results. The overall prevalence of respiratory ill-health symptoms was $34.1 \%$. The prevalence of respiratory ill-health conditions was significantly elevated among children from households using non-electrical fuels v. electricity for cooking ( $43.9 \%$ v. $31.6 \%$; adjusted $p$-value 0.005). The same was noted among those using non-electrical fuels for heating (37.8\% v. $29.0 \%)$.

Conclusion. The elevated prevalence of some respiratory health outcomes among schoolchildren, especially in conjunction with domestic fossil fuel burning, is of concern. The data collected in this study may be used to complement or form a basis for future policy regarding indoor or ambient air quality in the area.
\end{abstract}

S Afr Med J 2015;105(7):573-577. DOI:10.7196/SAMJnew.7934

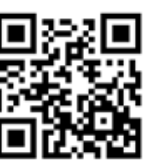

Children are particularly vulnerable with regard to exposure to both indoor and outdoor air pollution. They are also a high-risk group in terms of the illhealth outcomes associated with exposure to poor air quality. Their elevated vulnerability is attributable to their spending a relatively high proportion of their time in the home environment, which in South Africa (SA) may be an important source of air pollution from the combustion of solid and liquid fuels for daily cooking and space heating. Children also spend much time engaged in play and physical activities that cause them to breathe deeply and at an increased rate. ${ }^{[1]}$ In addition to the combustion of fossil fuels, indoor air quality may be affected by factors such as indoor smoking, emissions of volatile organic compounds from home furnishing and décor materials, poor ventilation, and the presence of mould and pests. Indoor air quality may also be affected by outdoor risk factors such as the proximity of dwellings to heavily used roads and proximity to industrial sites, power plants or mine tailings dams. ${ }^{[2,3]}$ For example, Dong et al..$^{[2]}$ found an association between respiratory morbidity in children and their proximity to traffic-related air pollution.

In developing countries such as SA, the indoor combustion of fossil fuels and the associated decline in indoor air quality is a major public health concern. According to a census undertaken in SA in 2011 , around $26 \%$ of households still use fuels other than electricity for daily cooking. ${ }^{[4]}$ A recent review on household air pollution and child survival concluded that reducing household air pollution could reduce the risk of acute lower respiratory infections (including severe and fatal pneumonia), low birth weight and stillbirth by up to $35 \% \cdot{ }^{[5]} \mathrm{A}$ risk factor analysis study undertaken in 2002 conservatively indicated that just over $1 \%$ of the burden of mortality in young children resulted from exposure to indoor air pollution, ${ }^{[6]}$ while a burden of disease study carried out in SA in 2012 showed that lower respiratory tract infections ranked among the top five causes of mortality in children under the age of 4 years. ${ }^{[7]}$

\section{Objective}

To undertake a cross-sectional analysis of domestic fuel use and child respiratory health and associated risk factors in two towns in Mpumalanga Province, SA. The towns are located in an area referred to as the Highveld Priority Area (HPA) because it has a recognised air pollution problem and it is believed that the populations living and working there are exposed to air that is harmful to their health and wellbeing.

\section{Methods}

The study was conducted in the towns of eMalahleni (formerly known as Witbank) and Middelburg. They are approximately $25 \mathrm{~km}$ apart. As part of the HPA initiative, air quality monitoring stations were set up in both eMalahleni and Middelburg.

A cross-sectional study was conducted during September 2010. The study population comprised children aged between 9 and 11 years attending grades 4 and 5 in public (government) primary schools. At this age males and females have similar and high breath rates of $14 \mathrm{~m}^{3} /$ day and $13 \mathrm{~m}^{3} /$ day, respectively, putting them at increased risk of the harmful effects of air pollution. ${ }^{[8]}$ Schools within a $10 \mathrm{~km}$ radius of the air quality monitoring stations in eMalahleni and Middelburg were selected for inclusion in the study. All schools in the study area were identified and ranked according 
to the total number of grade 4 and 5 learners. For logistic and economic reasons, the schools with the highest numbers of grade 4 and 5 students were preferred for inclusion until the required total sample size of 1334 was reached, involving four schools in eMalahleni and two in Middelburg. All children present on the day of fieldwork were given prestructured questionnaires in their preferred language (where possible) to take home for completion by their parents, caregivers or guardians.

A structured questionnaire, based on those used previously by Oosthuizen et

\begin{tabular}{|c|c|}
\hline Variable & $n / N(\%)^{*}$ \\
\hline \multicolumn{2}{|l|}{ Town } \\
\hline Witbank & $189 / 627(30.1)$ \\
\hline Middelburg & $438 / 627(69.9)$ \\
\hline \multicolumn{2}{|l|}{ Gender of the child } \\
\hline Female & $349 / 617(56.6)$ \\
\hline Male & $268 / 617(43.6)$ \\
\hline \multicolumn{2}{|l|}{ Language } \\
\hline Afrikaans & $13 / 621(2.1)$ \\
\hline English & $10 / 621(1.6)$ \\
\hline Zulu & $436 / 621(70.2)$ \\
\hline Sotho & $72 / 621(11.6)$ \\
\hline Other & $90 / 621(14.5)$ \\
\hline \multicolumn{2}{|l|}{ Type of housing } \\
\hline Brick dwelling & $476 / 574(82.9)$ \\
\hline Flat & $12 / 574(2.1)$ \\
\hline $\begin{array}{l}\text { Other (asbestos/wood/ } \\
\text { clay) }\end{array}$ & $86 / 574(15.0)$ \\
\hline \multicolumn{2}{|l|}{ Water source } \\
\hline Municipality & $573 / 618(92.7)$ \\
\hline Private borehole & $12 / 618(1.9)$ \\
\hline Community borehole & $33 / 618(5.3)$ \\
\hline \multicolumn{2}{|l|}{ Fuel used for cooking } \\
\hline Electricity & $459 / 614(74.8)$ \\
\hline Gas/paraffin (kerosene) & $48 / 614(7.8)$ \\
\hline Wood/coal & $107 / 614(17.4)$ \\
\hline \multicolumn{2}{|l|}{ Fuel used for heating } \\
\hline Electricity & $31 / 506(6.1)$ \\
\hline Gas/paraffin & $104 / 507(20.6)$ \\
\hline Wood/coal & $371 / 506(73.3)$ \\
\hline $\begin{array}{l}\text { Mould present inside the } \\
\text { house }\end{array}$ & $149 / 563(26.5)$ \\
\hline Smoking inside the house & $51 / 613(8.3)$ \\
\hline $\begin{array}{l}\text { Absent } 1 \text { or more days over } \\
\text { the past } 2 \text { weeks }\end{array}$ & $110 / 530(20.8)$ \\
\hline
\end{tabular}

al. ${ }^{[9]}$ and the Vaal Triangle Air Pollution and Health Study, was used for this study. ${ }^{[10]}$ These were based on those by Ferris (ATSDLD-78), ${ }^{[1]}$ the Canadian Air Quality and Health Study (NHW/HPB-190-03040), and the Harvard School of Public Health's Children's Health Study (NHW/HPB-19003210). The questionnaire, translated into Afrikaans and Zulu, included sections on demographic information, indoor risk factors (such as the fuels used for cooking and heating) and the child's health. A total of 1400 questionnaires was distributed to the schools.

\section{Ethical considerations}

The study was granted ethical approval by the University of Pretoria Ethics Committee on 12 April 2011 (S152/2010). The provincial Department of Education granted approval for the study to take place in the selected schools. Questionnaires were distributed together with a subject information sheet providing details of the study, explaining that participation was voluntary and could be withdrawn at any stage, and that completion and return of the questionnaire implied consent to participate.

\section{Data management and statistical analysis}

Returned questionnaires were assigned a unique code and entered into a prepared database in Epidata 3.1 (StataCorp, USA). Stata Statistical Software: Release 9 (StataCorp) was used to perform the statistical analysis. The age of the child was calculated using the date of birth and the date of fieldwork. Respondents falling outside the predetermined age range of 9 - 11 years were excluded. Univariate

Table 2. Prevalence of respiratory illhealth conditions $(N=627)$

\begin{tabular}{ll}
\hline Health outcome & $n / N(\%)^{*}$ \\
\hline Past 6 months & \\
Doctor diagnosed & \\
$\quad$ Bronchitis & $66 / 422(15.6)$
\end{tabular}

'Ever' during childhood to date

Doctor diagnosed

Asthma $39 / 551(7.1)$

Self-reported

Chest wheeze $59 / 519(11.4)$

Chest cough $45 / 445(10.1)$

Phlegm on the chest $123 / 481(25.6)$

Any respiratory $214 / 627(34.1)$

health condition

*Information missing for some children. analysis was carried out, including the calculation of frequencies and examination of missing data. Bivariate analysis using the $\chi^{2}$ test or Fisher's exact test was then undertaken; $p$-values, odds ratios (ORs) and the accompanying $95 \%$ confidence intervals (CIs) were examined in this step. Logistic regression was undertaken where risk factors were modelled with associated outcomes, adjusting for other associated risk factors. The results of the bivariate analysis were used to inform logistic regression using a $p$-value of 0.25 and biological plausibility. ${ }^{[12]}$ A probability for entry of 0.05 was used to maintain the strength of the models.

\section{Results}

Six schools participated in the study. A total of 859 completed questionnaires were returned, resulting in a response rate of $61.4 \%(859 / 1400)$. Only 627 of these were finally included in the analysis, because the remaining children fell outside the predefined age range.

Table 1 provides a profile of the study population (note that for many variables, information was missing for some children). The majority of the sample lived in the town of Middelburg, and girls outnumbered boys Three-quarters of the study subjects lived in dwellings in which the main fuel used for daily cooking was electricity, and a further $17.4 \%$ used coal. With regard to space heating, solid fuels (coal and wood) were most frequently used, while a relatively small proportion used electricity. A further 20.6\% used paraffin or gas to heat their homes. The majority (92.7\%) of dwellings were supplied with water through a reticulated municipal system. A relatively low percentage $(8.3 \%)$ of respondents reported that someone smoked inside the dwelling, and the presence of mould was reported in $26.5 \%$ of dwellings. A total of $20.8 \%$ of the children in the study were reported to have been absent from school on one or more days using a 2 -week recall period.

Table 2 gives the reported levels of selected respiratory ill-health outcomes (information missing for some children). Overall $16.5 \%$ of respondents said that the study child had been diagnosed by a doctor with the condition bronchitis in the preceding 6-month period; $25.6 \%$ of the children were reported to have had phlegm on their chests, and $21.5 \%$ to have suffered a chest cough or wheezing, using an 'ever' recall period. Thirty-four per cent of the study children had experienced a respiratory ill-health condition, over the past 6 months or 'ever', during their childhood to date. 
Respiratory ill-health burden in relation to fuel use

Table 3 gives a breakdown of reported respiratory ill-health conditions in relation to the type of fuel used for cooking and space heating (information missing for some children). There was a higher prevalence of any respiratory ill-health conditions among those using non-electrical fuels for cooking than among electricity users, with the prevalence being highest (45.5\%) among those using coal. The use of coal for cooking was associated with an increased prevalence of phlegm on the chest (36.9\% in coal users v. $23.5 \%$ in electricity users) and bronchitis (26.9\% v. $13.9 \%)$. The use of paraffin for cooking was associated with elevated levels of chest cough (25.7\%) and being absent from school for 1 or more days over the past 2 weeks (39.7\%). Levels of asthma did not vary according to the type of fuel used.

As was the case for cooking fuel, elevated levels of phlegm on the chest $(29.3 \%$ v. $15.8 \%$ in electricity users) and bronchitis $(19.7 \% \mathrm{v}$. $11.1 \%$ in electricity users) were reported in children from homes where wood and coal were used for space heating. Among gas and paraffin users, levels of wheezing (20.9\% v. $16.0 \%$ among electricity users) and asthma (11.6\% v. $7.1 \%$ among electricity users) were elevated.

Table 4 examines the relationship between respiratory ill health and cooking fuel types other than electricity. It is evident that overall, any respiratory ill-health condition was significantly associated ( $p=0.005$ ) with the use of non-electrical fuel sources for cooking. The relationship remained significant $(p=0.002)$ when controlling for town, having mould growth in the home and smoking in the home. Having phlegm on the chest was also significantly associated ( $p=0.029)$ with using non-electrical fuels for cooking, even after controlling for town, the presence of mould in the home and smoking $(p=0.018)$. Bronchitis was nearly significantly associated with cooking fuel at bivariate level $(p=0.061)$.

Table 5 examines the relationship between using wood or coal and gas or paraffin for space heating and respiratory ill-health outcomes. Having phlegm on the chest $(p=0.031)$ and bronchitis $(p=0.008)$ were significantly associated with using wood or coal at bivariate level, and remained significant ( $p=0.013$ and 0.007 , respectively) when controlling for town, mould growth in the home or smoking in the home. Having any respiratory condition and wood or coal burning was weakly associated at bivariate level, but became significant ( $p=0.018)$ after controlling for the other factors. Gas or paraffin use for space heating was significantly $(p=0.01)$ associated with only wheeze at bivariate level, and this remained significant $(p=0.018)$ when adjusting for other factors.

Table 3. Reported ill-health conditions according to main fuel used for cooking and space heating

\begin{tabular}{|c|c|c|c|c|c|c|c|}
\hline \multirow[b]{2}{*}{ Fuel used } & \multicolumn{7}{|c|}{ Ill-health conditions, $n / N(\%)^{\star}$} \\
\hline & Wheeze & $\begin{array}{l}\text { Phlegm on } \\
\text { chest }\end{array}$ & Chest cough & Bronchitis & Asthma & $\begin{array}{l}\text { Any respiratory } \\
\text { ill-health } \\
\text { condition }\end{array}$ & $\begin{array}{l}\text { Absent } 1 \text { or more } \\
\text { days over the } \\
\text { past } 2 \text { weeks }\end{array}$ \\
\hline \multicolumn{8}{|l|}{ Cooking } \\
\hline Electricity $(N=459)$ & $45 / 380(11.8)$ & $82 / 349(23.5)$ & $28 / 323(8.7)$ & $44 / 316(13.9)$ & $32 / 407(7.9)$ & $145 / 459(31.6)$ & $77 / 390(19.7)$ \\
\hline Gas/paraffin $(N=48)$ & $5 / 37(13.5)$ & $10 / 38(26.3)$ & $9 / 35(25.7)$ & $4 / 33(12.1)$ & $0 / 41(0.0)$ & $19 / 48(39.6)$ & $11 / 42(29.7)$ \\
\hline Wood/coal $(N=107)$ & $8 / 90(9.6)$ & $31 / 84(36.9)$ & $8 / 79(10.1)$ & $17 / 63(26.9)$ & $6 / 90(6.7)$ & $49 / 107(45.5)$ & $18 / 87(20.7)$ \\
\hline $\begin{array}{l}\text { Any fuel other than } \\
\text { electricity }(N=155)\end{array}$ & $13 / 127(10.2)$ & 41/122 (33.6) & $17 / 114(14.9)$ & 21/96 (21.9) & 6/131 (4.6) & 68/155 (43.9) & $29 / 129(22.5)$ \\
\hline \multicolumn{8}{|l|}{ Heating } \\
\hline Electricity $(N=31)$ & $4 / 25(16.0)$ & $3 / 19(15.8)$ & $2 / 19(10.5)$ & 2/18 (11.1) & $2 / 28(7.1)$ & $9 / 31(29.0)$ & $9 / 26(34.6)$ \\
\hline Gas/paraffin $(N=104)$ & $18 / 86(20.9)$ & $21 / 82(25.6)$ & $8 / 74(10.8)$ & 9/77 (11.7) & $10 / 86(11.6)$ & $40 / 104(38.5)$ & $21 / 92(22.8)$ \\
\hline Wood/coal $(N=371)$ & $32 / 296(10.8)$ & $82 / 280(29.3)$ & $29 / 256(11.3)$ & $46 / 233(19.7)$ & $23 / 320(7.2)$ & $136 / 354(38.4)$ & $65 / 298(21.8)$ \\
\hline $\begin{array}{l}\text { Any fuel other than } \\
\text { electricity }(N=431)\end{array}$ & $42 / 357(11.8)$ & 97/339 (28.6) & $35 / 309(11.3)$ & $50 / 287(17.4)$ & $30 / 383(7.9)$ & $163 / 431(37.8)$ & $80 / 368(21.7)$ \\
\hline
\end{tabular}

Table 4. $p$-values, ORs and 95\% CIs for the relationship between fuel used for cooking and respiratory ill-health outcomes

\begin{tabular}{|c|c|c|c|c|c|}
\hline \multirow[b]{2}{*}{ Health outcome } & \multicolumn{5}{|c|}{ Use of fuels other than electricity } \\
\hline & $n / N(\%)^{*}$ & $p$-value & OR $(95 \% \mathrm{CI})$ & $\begin{array}{l}\text { Adjusted } \\
p \text {-value }^{+}\end{array}$ & Adjusted OR $(95 \% \mathrm{CI})^{\dagger}$ \\
\hline Any respiratory ill-health condition & $68 / 155(43.9)$ & 0.005 & $1.69(1.16-2.47)$ & 0.002 & $1.88(1.25-2.82)$ \\
\hline Absenteeism & $29 / 129(22.5)$ & 0.504 & $1.18(0.72-1.91)$ & 0.837 & $1.06(0.62-1.81)$ \\
\hline Wheeze & $13 / 127(10.2)$ & 0.623 & $0.85(0.44-1.63)$ & 0.524 & $0.79(0.38-1.64)$ \\
\hline Phlegm on the chest & $41 / 122(33.6)$ & 0.029 & $1.65(1.04-2.59)$ & 0.018 & $1.81(1.11-2.94)$ \\
\hline Chest cough & 17/114 (14.9) & 0.059 & $1.85(0.96-3.53)$ & 0.128 & $1.74(0.85-3.53)$ \\
\hline Bronchitis & $21 / 96(21.9)$ & 0.061 & $1.73(0.96-3.09)$ & 0.180 & $1.56(0.81-2.97)$ \\
\hline Asthma & $6 / 131(4.6)$ & 0.202 & $0.56(0.22-1.34)$ & 0.296 & $0.58(0.21-1.61)$ \\
\hline
\end{tabular}


Table 5. $p$-values, ORs and 95\% CIs for the relationships between fuel used for space heating and respiratory ill-health outcomes

\begin{tabular}{|c|c|c|c|c|c|c|c|c|c|c|}
\hline \multirow[b]{2}{*}{ Health outcome } & \multicolumn{5}{|c|}{ Wood/ coal burning } & \multicolumn{5}{|c|}{ Gas/paraffin heater } \\
\hline & $\begin{array}{l}n / N \\
(\%)^{\star}\end{array}$ & $p$-value & OR $(95 \% \mathrm{CI})$ & $\begin{array}{l}\text { Adjusted } \\
p \text {-value }{ }^{\dagger}\end{array}$ & $\begin{array}{l}\text { Adjusted OR } \\
(95 \% \mathrm{CI})^{\dagger}\end{array}$ & $\begin{array}{l}n / N \\
(\%)^{*}\end{array}$ & $p$-value & OR $(95 \% \mathrm{CI})$ & $\begin{array}{l}\text { Adjusted } \\
p \text {-value }\end{array}$ & $\begin{array}{l}\text { Adjusted OR } \\
(95 \% \mathrm{CI})^{\dagger}\end{array}$ \\
\hline $\begin{array}{l}\text { Any respiratory } \\
\text { health condition }\end{array}$ & $\begin{array}{l}136 / 354 \\
(38.4)\end{array}$ & 0.071 & $\begin{array}{l}1.58 \\
(0.96-2.62)\end{array}$ & 0.018 & $\begin{array}{l}1.93 \\
(1.12-3.32)\end{array}$ & $\begin{array}{l}40 / 104 \\
(38.5)\end{array}$ & 0.197 & $\begin{array}{l}1.41 \\
(0.83-2.4)\end{array}$ & 0.322 & $\begin{array}{l}1.34 \\
(0.75-2.4)\end{array}$ \\
\hline Absenteeism & $\begin{array}{l}65 / 298 \\
(21.8)\end{array}$ & 0.131 & $\begin{array}{l}1.7 \\
(0.85-3.41)\end{array}$ & 0.104 & $\begin{array}{l}1.89 \\
(0.88-4.09)\end{array}$ & $\begin{array}{l}21 / 92 \\
(22.8)\end{array}$ & 0.304 & $\begin{array}{l}1.41 \\
(0.73-2.75)\end{array}$ & 0.837 & $\begin{array}{l}1.08 \\
(0.52-2.27)\end{array}$ \\
\hline Wheeze & $\begin{array}{l}32 / 296 \\
(10.8)\end{array}$ & 0.855 & $\begin{array}{l}0.93 \\
(0.42-2.04)\end{array}$ & 0.883 & $\begin{array}{l}1.07 \\
(0.43-2.65)\end{array}$ & $\begin{array}{l}18 / 86 \\
(20.9)\end{array}$ & 0.01 & $\begin{array}{l}2.82 \\
(1.24-6.41)\end{array}$ & 0.018 & $\begin{array}{l}2.67 \\
(1.18-6.02)\end{array}$ \\
\hline $\begin{array}{l}\text { Phlegm on the } \\
\text { chest }\end{array}$ & $\begin{array}{l}82 / 280 \\
(29.3)\end{array}$ & 0.031 & $\begin{array}{l}2.07 \\
(1.05-4.07)\end{array}$ & 0.013 & $\begin{array}{l}2.57 \\
(1.22-5.41)\end{array}$ & $\begin{array}{l}21 / 82 \\
(25.6)\end{array}$ & 0.238 & $\begin{array}{l}1.5 \\
(0.76-2.94)\end{array}$ & 0.293 & $\begin{array}{l}1.48 \\
(0.71-3.06)\end{array}$ \\
\hline Chest cough & $\begin{array}{l}29 / 256 \\
(11.3)\end{array}$ & 0.110 & $\begin{array}{l}2.85 \\
(0.84-9.73)\end{array}$ & 0.110 & $\begin{array}{l}2.76 \\
(0.79-9.57)\end{array}$ & $\begin{array}{l}8 / 74 \\
(10.8)\end{array}$ & 0.515 & $\begin{array}{l}1.38 \\
(0.52-3.69)\end{array}$ & 0.601 & $\begin{array}{l}1.3 \\
(0.48-3.49)\end{array}$ \\
\hline Bronchitis & $\begin{array}{l}46 / 233 \\
(19.7)\end{array}$ & 0.008 & $\begin{array}{l}3.16 \\
(1.28-7.78)\end{array}$ & 0.007 & $\begin{array}{l}3.79 \\
(1.45-9.92)\end{array}$ & $\begin{array}{l}9 / 77 \\
(11.7)\end{array}$ & 0.895 & $\begin{array}{l}0.94 \\
(0.39-2.26\end{array}$ & 0.896 & $\begin{array}{l}0.94 \\
(0.39-2.26)\end{array}$ \\
\hline Asthma & $\begin{array}{l}23 / 320 \\
(7.2)\end{array}$ & 0.989 & $\begin{array}{l}1.01 \\
(0.4-2.56)\end{array}$ & 0.823 & $\begin{array}{l}1.13 \\
(0.4-3.2)\end{array}$ & $\begin{array}{l}10 / 86 \\
(11.6)\end{array}$ & 0.249 & $\begin{array}{l}1.71 \\
(0.68-4.32)\end{array}$ & 0.253 & $\begin{array}{l}1.71 \\
(0.68-4.31)\end{array}$ \\
\hline
\end{tabular}

\section{Discussion}

This study aimed to explore fuel use and child respiratory health and associated risk factors in two towns in SA's Mpumalanga Province.

The results indicate that domestic use of non-electrical fuels for both cooking and space heating have negative consequences for child respiratory health, as seen by the increased prevalence of ill-health conditions reported in Table 3. The prevalence of any one of the examined respiratory ill-health conditions (wheeze, phlegm on the chest, chest cough, bronchitis or asthma) was $12.3 \%$ higher among children in whose homes non-electrical fuels were predominantly used for cooking. An 8.8\% increase in respiratory ill health was seen among those using non-electrical fuels for heating. The data indicate that paraffin (kerosene) had a greater influence on wheeze than wood or coal, as seen by the higher prevalence among those using it for either cooking or heating. Coal or wood use, for either cooking or heating, appears to be more strongly associated with the presence of phlegm on the chest and bronchitis. Having asthma and absenteeism did not appear to be strongly related to any particular fuel use, indicating other possible risks not examined here.

Statistics South Africa indicates that the number of households countrywide using electricity for cooking has increased since 1996 to just over $70 \%$ in $2011 .{ }^{[4]}$ Although the majority of this study population reported using electricity as their primary fuel for cooking, it is likely that many households still use multiple fuels to meet all their energy needs. ${ }^{[13]}$ For example, $93.9 \%$ of this study population reported using non-electrical fuels such as wood, coal, paraffin or gas for heating. Even though provided with electricity, this study population, and similar communities, are likely to remain at risk of exposure to indoor air pollution and the associated respiratory ill-health risks.

According to a burden of disease study in SA, which used data from 2007, lower respiratory tract infections (LRTIs) ranked as the second largest cause of death in children $<5$ years of age, accounting for $16.2 \%$ of deaths in this age group. ${ }^{[7]}$ For children aged 1 - 4 years, LRTIs ranked third highest, accounting for $15 \%$ of all deaths. The report also noted that mortality from LRTIs and other infectious diseases increased considerably over the 11-year period 1996 - 2007. A comparative risk assessment conducted by Norman et al. ${ }^{[14]}$ in 2007 to establish the burden of respiratory ill health in SA from indoor air pollution found that approximately $24 \%$ of acute respiratory tract infections in children under the age of 5 years were attributable to this risk factor, after adjusting for ventilation.

A similar study to the one reported in this article was conducted in the Vaal Triangle area of SA, showing the prevalence of upper respiratory disease in children aged $8-12$ years to be $66 \%$, while a prevalence of $29 \%$ was found for lower respiratory tract disease ${ }^{[10]}$ Data collected in Cape Town through the International Study of Asthma and Allergies in Children found a prevalence of $16 \%$ for asthma for the 13 - 14-year age group; this prevalence had increased to $20 \%$ approximately 5 years later. ${ }^{[15]}$ While Cape Town had a prevalence of $20 \%$, Limpopo Province in the north-east of SA had a prevalence of $18 \%{ }^{[16]}$ Furthermore, the prevalence of severe wheeze in Cape Town was $5 \%$ while in Limpopo it was $7 \%$. In a study including other African countries, Limpopo had the highest prevalence of wheeze. ${ }^{[17]}$ It is therefore evident that the results from this study are comparable to those from elsewhere in SA.

The findings reported in this paper serve to highlight the ongoing public health significance of exposure to indoor air pollution from the use of non-electrical fuels. Additionally, children living in areas such as the HPA are probably exposed to poor ambient air quality. In homes where fossil fuels are used for cooking or heating, children may be at increased risk of other injuries or illnesses such as burns from fires and poisoning from drinking paraffin. Death from carbon monoxide poisoning, as a result of open fires indoors being left unattended overnight, is also a concern.

Studies such as these may be used to lobby for accelerated action to improve residential air quality. Further research is needed to examine the impact on respiratory ill health of, for example, traffic-related pollution or specific industry-related sources of pollution.

\section{Study limitation}

A limitation of this study was the use of a self-completed questionnaire completed by the parent or guardian of the child to collect respiratory ill-health information retrospectively. This may have introduced response bias. 


\section{Conclusion}

The data presented here highlight the risk of respiratory ill health in children living in homes where fossil fuels are burnt indoors for cooking and space heating. There is a need for scaled-up action to ensure universal use of electricity, associated with poverty elimination in SA.

Acknowledgements. The authors thank the Council for Scientific and Industrial Research for funding this study and Juanette John and Loveness Dzikiti for statistical advice. They also thank the schools, principals, teachers, students and parents for participating in this study. This research was carried out as part of PNA's MSc degree in the School of Health Systems and Public Health, University of Pretoria.

Author contributions. PNA - study design, data collection, analysis and interpretation, paper write up; CYW - study design, data interpretation, paper write up; KVVV - study design, data interpretation, paper write up; AM - data interpretation, paper write up. All the authors read and approved the final manuscript.

\section{References}

1. Bearer CF. How are children different from adults? Environ Health Perspect 1995;103(6):7-12.

2. Dong GH, Ma YN, Ding HL, et al. Housing characteristics, home environmental factors and respiratory health in 3945 pre-school children in China. Int J Environ Health Res 2008;18(4):267-282. [http://dx.doi.org/10.1080/09603120701842864]

3. Thurstan GD. Outdoor air pollution: Sources, atmospheric transport, and human health effects. International Encyclopaedia of Public Health 2008;4:700-712.
4. Statistics South Africa, 2012. Statistical release P0301.4. http://www.statssa.gov.za/publications/ P03014/P030142011.pdf (accessed 26 May 2015).

5. Bruce NG, Dherani MK, Das JK, et al. Control of household air pollution for child survival: Estimates for intervention impacts. BMC Public Health 2013;13(Suppl 3):S8. [http://dx.doi.org/10.1186/1471-245813-S3-S8]

6. Norman R, Cairncross E, Witi I, et al. Estimating the burden of disease attributable to urban outdoor air pollution in South Africa in 2000. S Afr Med J 2007;97(8):782-790.

7. Nannan N, Dorrington RE, Laubscher R, et al. Under-5 Mortality Statistics in South Africa: Shedding Some Light on the Trends and Causes 1997-2007. Cape Town: South African Medical Research Council, 2012.

8. US Environmental Protection Agency, Exposure Factors Handbook. Washington, DC: National Centre for Environmental Assessment, 1997 .

9. Oosthuizen MA, Jinabhai CC, Terblanche APS, Beck PJ. A transition in health status from childhood to adulthood and associated lifestyle risk factors: A 13-year interval follow-up study in South Africa. International Journal of Environmental Health Research, 2008; 18(1): 65-72

10. Terblanche APS, Opperman L, Nel CME, et al. Preliminary results of exposure measurement and health effects of the Vaal Triangle Air Pollution Health Study. S Afr Med J 1992;81(11):550-556.

11. Ferris BG. Epidemiology Standardization Project. Contract No 1-HR-5-3028. Report HR-53028-F. New York: Division of Lung Diseases, National Heart, Lung and Blood Institute, USA, 1978.

12. Hosmer DW, Lemeshow S. Applied Logistic Regression. 2nd ed. Canada: John Wiley \& Sons, 2000.

13. Barnes B, Mathee A, Thomas E, Bruce N. Household energy, indoor air pollution and child respiratory health in South Africa. Journal of Energy in Southern Africa 2009;20(1):4-13.

14. Norman R, Barnes B, Mathee A, et al. Estimating the burden of disease attributable to Norman R, Barnes B, Mathee A, et al. Estimating the burden of disease attributable to
indoor air pollution from household use of solid fuels in South Africa in 2000. S Afr Med 2007;97(8):764-771.

15. Asher MI, Montefort S, Björkstén B, et al. Worldwide time trends in the prevalence of symptoms of asthma, allergic rhinoconjunctivitis, and eczema in childhood: ISAAC phases one and three repeat multicountry cross-sectional surveys. Lancet 2006;368(9537):733-743. [http://dx.doi.org/doi:10.1016/ S0140-6736(06)69283-0]

16. Ait-Khaled N, Odhiambo J, Pearce N, et al. Prevalence of symptoms of asthma, rhinitis and eczema in 13- to 14-year-old children in Africa: the International Study of Asthma and Allergies in Childhood Phase III. Allergy 2007;62(3):247-258. [http://dx.doi.org/10.1111/j.1398-9995.2007.01325.x]

17. Wichmann J, Wolvaardt JE, Maritz C, Voyi KVV. Household conditions, eczema symptoms and rhinitis symptoms: Relationship with wheeze and severe wheeze in children living in the 007-0309-x]

Accepted 11 June 2015. 